\title{
Application of Nonlinear Programming for Optimization of Nutrient Requirements for Maximum Weight Gain in Buffaloes
}

\author{
Pratiksha Saxena
}

School of Applied Sciences, Gautam Buddha University, Greater Noida, 201308, India

\begin{abstract}
In this paper, nonlinear effects of nutrient ingredients are introduced as an approach closer to the true effects of nutrient ingredients. A nonlinear model is developed to take consideration of nutrient ingredients more effectively. The nonlinear model is introduced in order to maximize the weight gain in buffalo by the optimal use of feed ingredients. Data from a variable caloric density study for buffalo is fitted to nonlinear objective function expression for weight gain of the animal in terms of feed ingredients. National Research Council requirements are introduced as constraints for mathematical model. Proposed model with nonlinear programming measures its performance and gives a comparative result with linear programming models. Thus the study is an attempt to develop a nonlinear programming model for optimal planning and best use of nutrient ingredients.
\end{abstract}

Keywords Nonlinear Programming, Nutrient Ingredients, Weight Gain, Feed Formulation, Feeding Standards

\section{Introduction}

Since 1940, the year of introduction of the concept of linear programming, fundamentals and applications of linear programming have been explored in great detail. In linear programming, all functional forms dealt with are linear in nature. While formulating a mathematical model related to real life problems, many different situations lead to nonlinear formulation of constraints and objective function. The importance of Nonlinear Programming Applications is growing due to rapidly increasing sophistication of managers and operation researchers in implementing decision oriented mathematical models, as well as to the growing availability of computer routines capable of solving large-scale nonlinear problems.

Animal diet formulation techniques are in use for more than hundred years. Objective of animal diet formulation is to provide necessary energy at different stages of production as growth, reproduction, metabolism and lactation.

Basic knowledge of animal nutrition, feed ingredient nutrition information, feed composition and diet formulation techniques are used to formulate the animal diet. Mathematical programming techniques are used to formulate the diet as linear programming, goal programming, multiple- objective programming, separable programming and nonlinear

\footnotetext{
* Corresponding author:

mathematics.pratiksha@gmail.com (Pratiksha Saxena)

Published online at http://journal.sapub.org/food

Copyright (C) 2011 Scientific \& Academic Publishing. All Rights Reserved
}

programming. Linear programming method is most widely used for this purpose. A linear model is developed (C. Van de Panne et al, 1963) to formulate optimise composition of cattle feed. Incorporation of information on animal performance into the linear programming derivation of optimum livestock rations is taken into consideration (Robert Townsley, 1968). Another model was developed using linear approximation of chance constrained programming (David L. Olson et al, 1987). A quadratic programming model is proposed (Bill R. Miller et al, 1986) and is compared to linear programming model. Focus is shifted to the application of nonlinear programming to the field of animal nutrition (Roush et al., 2007). Comparison between problem types, problem solving approaches and application was reported (Weintraub and Romero, 2006). A mixed-integer nonlinear programming technique is developed for the synthesis of model (Grossmann, 1990). Some of these models represent efficiency of converting any one of the nutrient ingredients to weight gain, while other represent a comparative study of effect of different nutrient ingredient on the weight gain of the animal. Thus, the data available depict the linear relationship between the weight gain and the nutrient ingredients individually, but complexity of different nutrient ingredients would possibly be better described by nonlinear relationship between them.

Introduction of nonlinear programming to optimize yield and minimize feed cost in buffalo feed formulation may lead to better approximation as compared to those of linear cases. Present study is carried out to extend the work by inclusion of this nonlinear relation. Leading to the same guideline a 
ration can be formulated using all its nutrient ingredients simultaneously at the optimum level. In this paper, it is envisaged to develop a mathematical model using non-linear programming to take simultaneous effects of all nutrient ingredients and the diet is optimized by using Kuhn- Tucker conditions. This result is also compared to than that of linear programming formulation of the model.

\section{Material and Methods}

The present study is based on the secondary data of animal experiment of Elangovan (1990). Briefly, the study consists of male buffalo calves of about 6-9 months of age, which were procured locally at Bareilly. Animals were dewormed and vaccinated against common contagious diseases. The animals were kept in a shed having cemented floor with individual feeding arrangement during the feeding trial but transferred to metabolic cages during metabolism trial. Drinking water was provided to all calves ad libitum. Three different feed treatments used in the experiment are given to animal which are shown in Table 1.

Table 1. Dietary treatment given to animals

\begin{tabular}{|c|c|c|c|}
\hline Feed & Control Group & \multicolumn{2}{|c|}{ Experimental Group } \\
\hline & I & II & III \\
\hline Block I & ---- & 500 gm & ---- \\
\hline Block II & ---- & ---- & ---- \\
\hline Deoiled rice bran & $1.5 \mathrm{~kg}$ & $1.5 \mathrm{~kg}$ & $1.5 \mathrm{~kg}$ \\
\hline Wheat bhoosa & $\underline{\mathrm{ad} \mathrm{lib}}$ & $\underline{\mathrm{ad} \mathrm{lib}}$ & $\underline{\mathrm{ad} \mathrm{lib}}$ \\
\hline
\end{tabular}

The animals were kept under these feeding regimens for 166 days. The calves were first fed on a standard farm ration for about two months period to make them healthier in order to avoid experimental error. The calves were offered feed, once in a day between 8.30 to 9.00 AM. Ad libitum drinking water was provided to all the calves twice a day. Animals were weighed on two consecutive days at fortnightly intervals before feeding and watering. The study parameters included digestibility of different nutrients as well as balances of nitrogen, calcium and phosphorus besides serum urea.

The present study is carried out to maximize the weight gain of the animal. The weight gain and the efficiency with which the nutrients are utilized mainly depend on several factors related to nutrient utilization (Maynard and Loosli, 1956), however weight gain of an animal mainly depends upon digestible crude protein (DCP), total digestible nutrient (TDN) and digestible dry matter (DM). Metabolic body weight is used as a base for all the calculations (Elliot and Toops, 1964). Input data for this work is represented in terms of three nutrient ingredients DCP, TDN and DM.

\section{Result and Discussion}

\subsection{Weightage of Variables}

First of all, linear relationship for dependent and inde- pendent variables is formulated to decide the weightage of the variables. Assuming a linear relationship between weight gain of buffaloes and intake of DM, CP and TDN, the weightage of these variables was decided.

Using least square method, the relationship is depicted in the following equation which describes the weightage of the variables $\mathrm{x}_{1}, \mathrm{x}_{2}$ and $\mathrm{x}_{3}$.

$$
\begin{aligned}
& y=2.00542 \times 10^{-1} x_{1}+3.648748 \times x_{2} \\
& -7.691844 \times 10^{-2} x_{3}+2.671533
\end{aligned}
$$

\subsection{Relationship between Variables}

By using least square method, the relations between y and $\mathrm{x}_{1}, \mathrm{y}$ and $\mathrm{x}_{2}, \mathrm{y}$ and $\mathrm{x}_{3}$ of different degrees were established and then by using F-test the relation of best fit was decided. Applying the F-test, the following most appropriate relationship between the variables were derived:

$$
\begin{gathered}
y=-3.454281 \times 10^{2}+2.174892 x_{1}-2.851922 \times 10^{-3} x_{1}^{2} \\
y=3.251281 \times 10^{1}+7.010015 \times 10^{-1} x_{2} \\
y=-1.954685 \times 10^{1}+2.424427 \times 10^{-1} x_{3}
\end{gathered}
$$

\subsection{Formulation of Objective Function}

The objective function was established by using the appropriate relations of the variables $\mathrm{x}_{1}, \mathrm{x}_{2}, \mathrm{x}_{3}$ according to their weightage on weight gain of the buffalo calves. The weightage with respect to total effect of this weightage was considered:

$$
\begin{aligned}
& Y=-17.77778869+0.131615729 x_{1} \\
& +0.077184052 x_{2}+5.627355208 \times 10^{-3} x_{3} \\
& -1.7258688661 \times 10^{-4} x_{1}^{2}
\end{aligned}
$$

\subsection{Constraints}

The constraints according to feeding standards on the above-mentioned variables according to feeding standards of NRC (1981) were applied

$$
\begin{gathered}
56.9 \leq \mathrm{x} 1 \leq 396.311 \\
7.6816 \leq \mathrm{x} 2 \leq 37.708 \\
220.4792 \leq \mathrm{x} 3 \leq 368.1687036
\end{gathered}
$$

\subsection{Problem Defined}

The main problem is formulated to maximise weight gain of the animal:

$$
\begin{aligned}
& Y=-17.77778869+0.131615729 x_{1}+0.077184052 x_{2} \\
& +5.627355208 \times 10^{-3} x_{3}-1.725868661 \times 10^{-4} x_{1}^{2}
\end{aligned}
$$

subject to:

$$
\begin{gathered}
56.9 \leq \mathrm{x} 1 \leq 396.311 \\
7.6816 \leq \mathrm{x} 2 \leq 37.708 \\
220.4792 \leq \mathrm{x} 3 \leq 368.1687036
\end{gathered}
$$

\subsection{Solution of the Problem}

Introducing Kuhn-Tucker conditions, the weight gain of the buffalo calves could be maximized as: 


$$
\begin{aligned}
& L=-17.77778869+0.131615729 x_{1}+0.077184052 x_{2} \\
& +5.627355208 \times 10^{-3} x_{3}-1.725868661 \times 10^{-4} x_{1}^{2} \\
& -\lambda_{1}\left(x_{1}-396.311\right)-\lambda_{2}\left(x_{2}-37.708\right)-\lambda_{3}\left(x_{3}-368.1687036\right)
\end{aligned}
$$

Using Kuhn-Tucker conditions, the following set of equations were obtained for optimal solutions:

1. $0.70752862-1.855555531 \times 10^{-3} x_{1}-\lambda_{1}=0$

2. $0.393301399-\lambda_{2}=0$

3. $0.027548012-\lambda_{3}=0$

4. $\lambda_{1}\left(x_{1}-396.311\right)=0$

5. $\lambda_{2}\left(x_{2}-37.708\right)=0$

6. $\lambda_{3}\left(x_{3}-368.168706\right)=0$

7. $\mathrm{x}_{1} \leq 396.311$

8. $x_{2} \leq 37.708$

9. $\mathrm{x}_{3} \leq 368.1687036$

10. $\lambda_{1}, \lambda_{2}, \quad \lambda_{3} \geq 0$

Solving these equations the optimum values of the three nutrients is found out to maximize the body weight gain. Accordingly we have:

$$
\mathrm{x}_{1}=381.3028, \mathrm{x}_{2}=7.708, \mathrm{x}_{3}=368.1687036 \mathrm{~g} / \mathrm{kg} \mathrm{W}^{0.75}
$$

It also gives, $\lambda_{1}=0.393301399, \lambda_{2}=0.027548012$ which satisfied all the conditions.

The problem is also formulized and solved by simplex method and it gives,

$\mathrm{x}_{1}=396.311, \mathrm{x}_{2}=37.708, \mathrm{x}_{3}=368.1687036 \mathrm{~g} / \mathrm{kg} \mathrm{W}^{0.75}$

Comparison shows that by linear programming result is obtained at corner points of feasible area and optimization is at comparatively at higher values of nutrient ingredients. This comparison represents that non-linear programming is better way to take simultaneous effect of all nutrient ingredients together and maximize the weight gain in animal with optimized value of nutrient ingredients.

\section{Conclusions}

Comparison of the present nonlinear method with linear programming represents that nonlinear programming gives maximum weight gain with optimum use of nutrients. The effect of these nutrients on body weight gain was considered and individual relations as obtained in equations present the linear and nonlinear effects of different ingredient on body weight gain.

\section{REFERENCES}

[1] C. Van de Panne, W. Popp. "Minimum-Cost Cattle Feed Under Probabilistic Protein Constarints". Management Science. Vol. 9, Issue 3, pp. 405-430, 1963

[2] Robert Townsley (1968). Derivation of optimal livestock rations using quadratic programming. Journal of Agricultural Economics. 19(3): 347-354

[3] David L. Olson and Scott R. Swenseth (1987).A Linear Approximation for Chance-Constrained Programming. J Operational Research Society. 38(3): 261-267

[4] Bill R. Miller, Ronaldo A. Arraes, Gene M. Pesti (1986). Formulation of Broiler Rations by Quadratic Programming. Southern J Agricultural Economics. 141-151

[5] Roush, W. B., Purswell J. and Branton, S. L. "Adjustable nutrient margin of safety comparison using linear and stochastic programming in an Excel spreadsheet", Journal of Applied Poultry Research, Vol. 16, pp. 514-520, 2007

[6] Weintraub, A. and Romeo, Operations research models and the management of agricultural and forestry resources: A review and comparison”. Interfaces, Vol. 36, pp. 446-457, 2006

[7] Grossmann, I. E. "J. Breckling, Ed. "Mixed-integer nonlinear programming techniques for the synthesis of engineering systems" Research in Engineering Design, Vol.1, pp. 205-228, 1990

[8] Elangovan, A.V. "Nutrient Utilization and Growth Performance in Buffalo Calves Fed on Wheat Bhoosa and Oil Extracted Rice Bran Supplemented with Urea-molasses Cake”. MVSc Thesis, Indian Veterinary Research Institute, Izzatnagar, India, 1990

[9] Elliot, R. C. and Toops. "Studies of Protein requirements of ruminants". British Journal of Nutrition, Vol. 18, pp. 245-249, 1964

[10] Maynard L. A. and Loosli, J. K. Animal Nutrition, Tata McGraw Hill, pp. 138-145, 1956.

[11] NRC, Report of Commission on Natural Resources, National Research Council, National Academy Press, Washington, DC, 1981 